\title{
Bronchoscopic treatment of inoperable nonsmall cell lung cancer
}

\author{
Christopher M. Kniese ${ }^{1}$ and Ali I. Musani ${ }^{2}$ \\ Number 3 in the Series "Interventional pulmonology" \\ Edited by David Feller-Kopman and Hervé Dutau
}

\begin{abstract}
Affiliations: ${ }^{1}$ Division of Pulmonary, Critical Care, Sleep, and Occupational Medicine, Indiana University School of Medicine, Indianapolis, IN, USA. ${ }^{2}$ Division of Pulmonary Sciences and Critical Care, University of Colorado School of Medicine, Aurora, CO, USA.
\end{abstract}

Correspondence: Ali I. Musani, Division of Pulmonary Sciences and Critical Care, University of Colorado School of Medicine, E 17th Ave Rm\# 9119 RC2, Aurora, C0 80045, USA. E-mail: Ali.Musanidcuanschutz.edu

@ERSpublications

PDT and EBBT may be effective options for early-stage NSCLC. PDT, EBBT, debulking and stenting may be offered to patients receiving definitive treatment or for palliation. Respiratory failure is not a contraindication to therapeutic bronchoscopy. https://bit.ly/2SmhtEQ

Cite this article as: Kniese CM, Musani AI. Bronchoscopic treatment of inoperable nonsmall cell lung cancer. Eur Respir Rev 2020; 29: 200035 [https://doi.org/10.1183/16000617.0035-2020].

ABSTRACT Patients with unresectable lung cancer range from those with early-stage or pre-invasive disease with comorbidities that preclude surgery to those with advanced stage disease in whom surgery is contraindicated. In such cases, a multidisciplinary approach to treatment is warranted, and may involve medical specialties including medical oncology, radiation oncology and interventional pulmonology. In this article we review bronchoscopic approaches to surgically unresectable lung cancer, including photodynamic therapy, brachytherapy, endoscopic ablation techniques and airway stenting. Current and past literature is reviewed to provide an overview of the topic, including a highlight of potential emerging approaches.

\section{Introduction}

Lung cancer remains the leading cause of cancer deaths in the United States, responsible for 148869 deaths in 2016 [1]. Fortunately, the incidence is declining in recent years, probably owing to declines in tobacco use over the past few decades [2]. Nonsmall cell lung cancers (NSCLC) account for up to $80 \%$ of all lung cancer cases in the United States [3]. There are many new advances in the management of NSCLC, including immunotherapy and targeted therapeutics for patients with identifiable molecular mutations. However, chemotherapy, radiation and surgical excision remain the mainstays of treatment [4]. Unfortunately, up to $70 \%$ of patients have locally advanced or metastatic disease at the time of diagnosis [3]. Many of these patients are therefore not considered surgical candidates, and thus require a multidisciplinary approach to manage their disease.

The staging of lung cancer has evolved, with the most updated classification system being the eighth edition of the tumor, node and metastasis (TNM) staging system put forth by the International

Provenance: Commissioned article, peer reviewed.

Previous articles in this series: No. 1: DeMaio A, Sterman D. Bronchoscopic intratumoral therapies for nonsmall cell lung cancer. Eur Respir Rev 2020; 29: 200028. No. 2: Chandrika S, Yarmus L. Recent developments in advanced diagnostic bronchoscopy. Eur Respir Rev 2020; 29: 190184.

Received: 04 Feb 2020 | Accepted after revision: 24 April 2020

Copyright CERS 2020. This article is open access and distributed under the terms of the Creative Commons Attribution Non-Commercial Licence 4.0. 
Association for the Study of Lung Cancer. Patients with advanced-stage disease (stages IIIa-IV) are often considered surgically unresectable; thus, alternative approaches to treatment are needed. Chemotherapy and radiation remain the mainstays of treatment for patients who are not surgical candidates; however, these are often inadequate to fully manage symptoms and complications of advanced disease, particularly airway obstruction. In such patients, the interventional pulmonologist can play an integral role in the multidisciplinary approach to lung cancer management.

Bronchoscopic modalities to treat lung cancer have been used for decades and include options such as ablative techniques and airways prostheses. These techniques are generally considered adjunctive therapies in patients undergoing curative-intent treatment. However, they are often also indicated for palliation of symptoms in patients with advanced or incurable disease, particularly those with malignant airway obstruction. For a subset of patients with early-stage disease, modalities such as photodynamic therapy (PDT) or brachytherapy may be used as definitive therapy. In this article we review bronchoscopic techniques for treatment of inoperable NSCLC, with a focus on indications, mechanism of action and efficacy.

\section{Epidemiology of inoperable NSCLC}

Lung cancer remains a major source of morbidity and mortality on the world stage. Cigarette smoke continues to be the leading cause of lung cancer mortality worldwide, despite reductions in smoking prevalence over time [2,5]. The advent of low-dose computed tomography scanning for lung cancer screening has led to increased detection of earlier stage disease [6]. However, in the United States only a small portion of eligible patients actually undergo screening, and thus many lung cancer cases are still diagnosed at a late stage $[7,8]$.

Limited data exist on the true incidence of unresectable disease in new cases of NSCLC. A recent analysis using data from the Surveillance, Epidemiology, and End Results database from 2010 to 2016 sought to assess the incidence of metastatic disease in lung cancer at time of diagnosis and evaluate survival and prognostic factors [9]. In this analysis, bone was the most common site of metastasis, with an incidence of nine cases per 100000 people, followed by lung, liver and brain [9]. Most patients with distant metastatic disease are not surgical candidates $[10,11]$.

For those patients diagnosed with early-stage disease without distant nodal or organ system metastases, surgery remains the definitive treatment [12]. In those patients with unresectable disease, chemotherapy and radiation are the mainstays of treatment [4]. Patients may be deemed unresectable for multiple reasons, whether it be metastatic disease, size of tumour, involvement of vital structures in the chest and mediastinum or comorbidities. A significant portion of these patients may suffer from malignant central airway obstruction or endobronchial disease involving the lobar or segmental bronchi [13]. Endoscopic management is often required in such patients [14]. Bronchoscopic modalities include ablative therapies aimed at destroying tumour tissue and restoring airway patency, stents designed to augment airway patency, and, in selected patients, ablative manoeuvres to definitively treat early-stage disease [15]. The choice of modality depends on the nature of obstruction (extrinsic, endoluminal or mixed disease) as well as tumour location [14]. In the following sections we review several such bronchoscopic treatment options.

\section{Photodynamic therapy}

PDT refers to the combination of a photosensitising agent and light exposure to treat malignant lesions [16]. PDT is not new, and its application in lung cancer has been reported dating back to the 1980s [17]. PDT relies on the cytotoxic effects of reactive oxygen species, and the first step is intravenous administration of the photosensitising agent to the patient, most commonly porfimer sodium [18]. The guiding principle is that malignant tissues are thought to retain the agent at higher concentration and for longer duration than normal tissues [19]. After $48-72 \mathrm{~h}$, the light source is then applied to the target lesion to generate the reactive oxygen species and initiate tumour destruction through cellular death [2022]. The light application is commonly performed using a fibreoptic laser diffuser and is applied through either flexible or rigid bronchoscopy to achieve a target dose of $50-300 \mathrm{~J} \cdot \mathrm{cm}^{-1}$ of airway treated $[16,23]$. Follow-up bronchoscopy is often required in the days following light application for debridement and removal of necrotic tissue from the airways [24].

Indications for PDT in NSCLC include patients with symptomatic obstruction of proximal airways as well as superficial lesions, including early-stage or superficial carcinoma in situ lesions that can be accessed endoscopically [21]. PDT is often used in combination with systemic chemotherapy or radiation, but here we focus on endobronchial disease. Patient selection is important, as not all forms of airway obstruction are appropriate for PDT. Patients with predominantly extrinsic compression should not undergo PDT and may be more appropriate for alternative therapies such as stenting. In general, the available light sources are only able to penetrate $5-10 \mathrm{~mm}$, thus lesions longer or deeper than this may not be fully treated with 
PDT $[21,25]$. In addition, lesions adjacent to vascular structures carry a risk of complications, including haemorrhage [26]. Endobronchial ultrasound (EBUS) may be used to inspect the lesion and adjacent airways for depth of tumour invasion, as well as identification of adjacent structures [27]. Airway patency beyond the obstruction should be assessed to ensure an appropriate expectation of benefit from the procedure. Patients with life-threatening obstruction should be offered an alternative approach such as thermal ablation or mechanical debulking given that the effects of PDT are not immediate.

Numerous studies have demonstrated the safety and efficacy of PDT in NSCLC, although the literature is heterogenous in terms of patient populations and mostly observational in nature. A summary of pertinent studies and their outcomes is provided in table 1. Hugh-Jones and Gardner [28] reported experience in 15 patients with squamous cell carcinoma and airway obstruction, with $75 \%$ of patients achieving at least partial relief of obstruction and complete relief in 25\%. KATO et al. [17] reported on PDT in 240 patients with early-stage bronchogenic carcinoma, with $83 \%$ of patients achieving complete remission. MogHISSI et al. [20] demonstrated 67\% mean improvement in airway obstruction, as well as improvements in lung function parameters and performance status in 100 patients with malignant airway obstruction, the majority of whom had NSCLC. Similar, but more dramatic results were reported more recently in a series by CAi et al. [33]. Studies assessing survival benefit are mixed. McCaUghan and Williams [24] reported on 175 patients with advanced-stage NSCLC treated with PDT, with 5-month median survival in patients with stage IV disease. Conversely, Moghissi et al. [31] reported separately on PDT treatment in 21 patients with early central NSCLC and achieved a mean survival of 39 months. MinNich et al. [32] reported on PDT treatment in 133 patients, with median survival of 4.4 years, although the patients included were heterogenous, and PDT was often combined with other treatment modalities including additional ablative methods. It's important to note that the majority of these studies were not specifically designed or powered for survival analysis, and survival largely depended on clinical stage at the time of treatment. Lastly, a small study comparing PDT to neodymium-doped yttrium aluminium garnet (Nd-YAG) laser in patients with NSCLC, PDT and laser showed similar efficacy at relieving obstruction, but PDT showed a slightly longer time to treatment failure [30].

A unique aspect of PDT that deserves special attention is the potential for photosensitivity, which can occur in patients for up to $4-6$ weeks following treatment $[22,34]$. However, the reported incidence is low, and patients should be counselled extensively on the need to avoid direct sunlight during the follow-up period. PDT remains under investigation in a several different clinical scenarios. PDT can be feasibly be

TABLE 1 Highlighted studies of photodynamic therapy in lung cancer

\section{First author}

[reference]

\section{Year}

Study subjects

Outcome measure(s)

Results

\begin{tabular}{|c|c|c|c|}
\hline HUGH-Jones [28] & 1987 & $\begin{array}{l}15 \text { patients, squamous } \\
\text { cell carcinoma }\end{array}$ & Airway obstruction \\
\hline КАто [17] & 1996 & $\begin{array}{l}240 \text { patients, } \\
\text { bronchogenic carcinoma }\end{array}$ & Complete remission \\
\hline $\begin{array}{c}\text { CoRTESE } \\
\text { [29] }\end{array}$ & 1997 & $\begin{array}{l}21 \text { patients, squamous } \\
\text { cell carcinoma }\end{array}$ & Complete response \\
\hline McCaughan [24] & 1997 & 175 patients with NSCLC & Survival, KPS \\
\hline
\end{tabular}

$\begin{array}{lcc}\text { Moghissı [20] } & 1999 & \begin{array}{c}100 \text { patients: } 90 \text { with } \\ \text { NSCLC, 10 SCLC }\end{array} \\ \text { Diaz-JimÉnez [30] } & 1999 & \text { 14 patients with NSCLC }\end{array}$

MoghIssı [31]

21 patients, early central lung cancer, NSCLC

MinNich [32]

2010

133 patients, NSCLC

$\mathrm{CAI}_{\mathrm{Al}}[33]$

2013
Percentage of obstruction, FVC, $\mathrm{FEV}_{1}$, WHO performance status Time to recurrence, symptoms compared to $\mathrm{Nd}$-YAG laser resection

Complete response, survival

Mean mMRC dyspnoea scale, complications, survival

Total response, mean tumour obstruction, KPS
Complete relief of obstruction in $25 \%$, partial relief in remaining $75 \%$

Complete remission obtained in $83.2 \%$ of early-stage lesions

Complete response lasting 12 months obtained in $52 \%$

Median survival by clinical stage: Illa 5.7 months, IIIb 5.5 months, IV 5 months; KPS had significant impact on survival

$67 \%$ mean improvement in obstruction, improvements in $\mathrm{FEV}_{1}, \mathrm{FVC}$ and performance status Similar efficacy, PDT showed longer time to treatment failure (50 versus 38 days)

Complete response in $100 \%$, mean survival 39.3 months

Mean mMRC improved from 3 to 2.7, complications in $15 \%$, median survival 4.4 years

Total response in $86.7 \%$, mean tumour obstruction decreased from $90 \%$ to $16.7 \%$, mean KPS increased from 40 to 80

NSCLC: nonsmall cell lung cancer; KPS: Karnofsky Performance Score; SCC: small cell lung cancer; FVC: forced vital capacity; FEV 1 : forced expiratory volume in $1 \mathrm{~s}$; WHO: World Health Organization; Nd-YAG: neodymium-doped yttrium aluminium garnet; mMRC: modified Medical Research Council. 
combined with endobronchial brachytherapy in patients with symptomatic disease who are not candidates for other therapies [35]. In addition, there is emerging interest in PDT to treat peripheral lung tumours. A recent animal study demonstrated the feasibility of using navigation bronchoscopy to deliver PDT treatments to peripheral lesions [36]. Thus, applications for PDT are likely to continue to grow as bronchoscopic technology evolves.

\section{Brachytherapy}

Brachytherapy refers to the delivery of radiation in localised fashion to target tissues in order to avoid undue exposure to nearby tissues [37]. Endobronchial brachytherapy (EBBT) has been used in NSCLC for many years as a palliative treatment in those patients not candidates for definitive therapy and as a definitive treatment in patients with early-stage disease [37]. Although not uniformly available, EBBT is considered a standard part of the treatment algorithm for patients with symptomatic endobronchial disease who may not be candidates for external beam radiotherapy or surgical resection [38]. In addition, similarly to PDT, EBBT is included in the 2013 American College of Chest Physicians guidelines for treatment of bronchial intraepithelial neoplasia and early stage central lung cancers [25]. EBBT involves placement of a specialised catheter into the airway adjacent to the target lesion, generally accomplished using flexible bronchoscopy. The bronchoscope is removed from the airway with the catheter secured in place, and radiation is delivered to the target tissue after appropriate planning is performed. Both highand low-dose formulations have been described, although the high-dose approach is most often employed in the present day due to better efficacy, and iridium-192 is the most common radioactive material used [38]. The catheter is removed at bedside once the radiation dose has been delivered and patients are generally discharged home the same day.

Indications for EBBT include as palliation of symptomatic airway obstruction, and potentially definitive treatment for superficial malignant or pre-malignant airway lesions. Like PDT, EBBT is best suited for malignant obstruction that is predominantly endobronchial in nature, though it can be used for some cases of extrinsic compression when the majority of the lesion is adjacent to the airway. EBBT should not be used as first-line treatment for those patients who require rapid relief of airway obstruction as treatment effects will not be fully realised for up to 2-3 weeks [23]. In addition, it is important to acknowledge that EBBT should not be viewed as equivalent to external beam radiotherapy (EBRT), as multiple head-to-head studies have shown that EBRT is superior in terms of symptom relief and potentially disease-free survival in patients with malignant airway obstruction $[39,40]$. Thus, the list of indications for EBBT in NSCLC is narrow in the modern age of cancer therapy.

Major studies demonstrating the effectiveness of EBBT are summarised in table 2. Lo et al. [41] reported on 87 patients with malignant endobronchial disease, $59 \%$ of whom showed improvement in symptoms or degree of obstruction after EBBT. Similarly, the following year another study of 32 patients with endobronchial disease demonstrated subjective improvements in cough and haemoptysis [42]. A larger study by Taulelle et al. [45] included 189 patients, 177 of whom had NSCLC. In this study, 54\% had significant improvement in airway obstruction, $72 \%$ had improvement in symptoms, but median survival was only 5.2 months [45]. Another study of 175 patients, 167 of whom had NSCLC showed $66 \%$ with improvement in symptoms, with mean survival of 6 months [47]. A more recent study by HENNEQUIN et al. [49] focused on histological response and local disease control. In this study of 106 patients with lung cancer, $59 \%$ of patients showed complete histologic response at 2 months' follow-up, and 52\% had local control at 5 years, with $49 \%$ cause-specific 5-year survival [49]. One of the largest studies, by AUMONT-LE GUILCHER et al. [51] included 226 patients with NSCLC, with promising results that included $91 \%$ of subjects with complete response at 3-month follow-up and 50\% disease-free survival at 5 years. Lastly, one small prospective study compared Nd-YAG laser treatment to combined laser and EBBT in patients with inoperable lung cancer and found that the group receiving EBBT plus laser had long duration of symptom relief (8.5 months versus 2.8 months) and longer progression-free survival ( 7.5 months versus 2.2 months) compared to laser alone, highlighting the potential for EBBT to be used as adjunct therapy in certain patients [53].

These studies suggest that EBBT can be effective at relieving symptomatic airway obstruction and achieving local disease control in selected patients with NSCLC. The survival data are less compelling, and studies included patients with various stages of disease. As previously stated, EBBT should not be considered equivalent to EBRT when that is an available option. Complications of brachytherapy include those from bronchoscopy itself, catheter dislodgement, and those from local tissue effects of brachytherapy. One study assessing complications of EBBT in 761 patients showed $5.4 \%$ rate of complications at 3 weeks [54]. The most common was hypoxia, seen in $1.7 \%$, following by haemoptysis in $1.1 \%$ [54]. A separate small study showed a much higher rate of bleeding, with massive haemoptysis occurring in $29 \%$ of patients [55]. The authors concluded that contact between the catheter and airway 
TABLE 2 Highlighted studies of brachytherapy in lung cancer

\begin{tabular}{|c|c|c|c|c|}
\hline $\begin{array}{l}\text { First author } \\
\text { [reference] }\end{array}$ & Year & Study subjects & Outcome measure(s) & Results \\
\hline Lo [41] & 1992 & $\begin{array}{l}87 \text { patients with } \\
\text { malignant endobronchial } \\
\text { disease }\end{array}$ & Treatment response & $\begin{array}{l}59 \% \text { with improvement in symptoms or airway } \\
\text { obstruction }\end{array}$ \\
\hline NoRI [42] & 1993 & $\begin{array}{c}32 \text { patients with } \\
\text { endobronchial disease, } 30 \\
\text { with lung cancer }\end{array}$ & $\begin{array}{c}\text { Symptom improvement, performance } \\
\text { status }\end{array}$ & $\begin{array}{l}\text { Improvements in cough, haemoptysis and } \\
\text { performance status }\end{array}$ \\
\hline Ofiara [44] & 1997 & $\begin{array}{c}30 \text { patients with lung } \\
\text { cancer and endobronchial } \\
\text { disease }\end{array}$ & $\begin{array}{l}\text { Radiographic degree of atelectasis, } \\
\text { symptoms, performance status, } \\
\text { bronchoscopic evidence of } \\
\text { obstruction }\end{array}$ & $\begin{array}{l}54 \% \text { with improvement in atelectasis; } 63 \% \text { with } \\
\text { bronchoscopic improvement in obstruction; } \\
79 \%, 46 \% \text { and } 33 \% \text { with improvement in } \\
\text { haemoptysis, cough and dyspnoea, respectively }\end{array}$ \\
\hline TauleLle [45] & 1998 & 189 patients, 177 NSCLC & $\begin{array}{c}\text { Symptom improvement, survival, } \\
\text { toxicity }\end{array}$ & $\begin{array}{c}\text { Majority had improvement in dyspnoea (54\%), } \\
\text { cough (54\%), and haemoptysis ( } 76 \%) \text {; median } \\
\text { survival } 7 \text { months; } 26 \% \text { with serious toxicity at } \\
18 \text { months }\end{array}$ \\
\hline KelLy [47] & 2000 & $\begin{array}{l}175 \text { patients with lung } \\
\text { cancer, } 167 \text { NSCLC }\end{array}$ & Survival, symptom improvement & $\begin{array}{l}\text { Mean survival } 6 \text { months, improved survival in } \\
\text { those with symptom improvement; } 66 \% \text { with } \\
\text { symptom improvement }\end{array}$ \\
\hline GEJeRMAN [48] & 2002 & $\begin{array}{l}41 \text { patients, } 33 \text { with } \\
\text { primary lung cancer }\end{array}$ & $\begin{array}{l}\text { Relief of obstruction, symptom } \\
\text { improvement, survival }\end{array}$ & $\begin{array}{l}54 \% \text { with significant improvement in } \\
\text { obstruction; } 72 \% \text { with significant symptom } \\
\text { improvement; median survival } 5.2 \text { months }\end{array}$ \\
\hline Hennequin [49] & 2007 & $\begin{array}{l}106 \text { patients with lung } \\
\text { cancer }\end{array}$ & $\begin{array}{c}\text { Histologic response, local control, } \\
\text { survival }\end{array}$ & $\begin{array}{c}59 \% \text { had complete histologic response at } \\
2 \text { months; } 52 \% \text { with local control at } 5 \text { years; } \\
24 \% 5 \text {-year survival, } 49 \% \text { cause-specific } 5 \text {-year } \\
\text { survival }\end{array}$ \\
\hline $\begin{array}{l}\text { GuARNASCHELLI } \\
\text { [50] }\end{array}$ & 2010 & $\begin{array}{l}52 \text { patients with } \\
\text { endobronchial tumours }\end{array}$ & $\begin{array}{l}\text { Symptom improvement, survival, } \\
\text { complications }\end{array}$ & $\begin{array}{c}92 \% \text { experienced symptom relief; median } \\
\text { survival } 7 \text { months; } 4 \% \text { with major complications }\end{array}$ \\
\hline
\end{tabular}

wall adjacent to the great vessels substantially increased bleeding risk [55]. Lastly, airway fistulisation with adjacent structures is a well-recognised complication [56]. Thus, important consideration should always be given to risks and benefits when contemplating EBBT.

\section{Laser therapy}

Patients with unresectable NSCLC presenting with endobronchial disease are often evaluated for bronchoscopic intervention using local ablative modalities. These range from noncontact modalities including laser and argon plasma coagulation (APC) to contact methods including electrosurgery and cryoablation [57]. These techniques are often used in combination with chemotherapy, radiation, and in select cases airway stenting for immediate relief of obstruction [57]. In this section we briefly review select modalities available to the interventional pulmonologist.

Laser therapy for cancer treatment has been well described for several decades and involves the application of light energy to tumour using a catheter in a noncontact fashion [58]. Various lasers are available for commercial use, and they all differ somewhat in their exact properties regarding depth of tissue penetration as well as coagulation and vaporisation effects [57]. The most widely used laser in clinical practice is the Nd-YAG laser, preferred for its excellent coagulation and vaporisation properties. Multiple series have documented the effectiveness of laser therapy for relief of endobronchial obstruction in benign and malignant conditions $[59,60]$. Laser can be applied through either the flexible or rigid bronchoscope, 
although in clinical practice rigid bronchoscopy is often preferred [58]. In patients with NSCLC, laser therapy can be used for treatment of airway obstruction when surgical treatment is precluded. The use of laser requires a fraction of inhaled oxygen $\left(F_{\mathrm{iO}_{2}}\right)<0.4$ to reduce the risk of airway fire, a rare but serious complication of thermal ablative modalities.

\section{Argon plasma coagulation and electrosurgery}

APC and electrosurgery are additional forms of thermal ablation available to the bronchoscopist. Both use monopolar current via a generator and thus require a grounding pad be placed on the patient for appropriate dispersion of current. APC is a noncontact form of thermal ablation whereby argon gas is used as a conduit to transfer heat energy via electrical current to target tissue and was adapted for endoscopic use after initial applications in open surgery [61, 62]. Often selected for its excellent haemostatic effects, APC generally has a lower depth of tissue penetration compared to laser [57]. APC is frequently applied via the flexible bronchoscope and may be used in combination with additional ablative modalities. APC may be effectively utilised in cases of malignant airway obstruction [63, 64]. Electrosurgery also uses monopolar current to deliver heat energy to target tissue, but is applied via direct contact with tissue, leading to tissue coagulation and tissue destruction [57,62]. Electrosurgery may also be applied via flexible or rigid bronchoscopy, or often using a flexible scope through the rigid bronchoscope. Common tools include a probe for contact ablation, a snare for tumour removal and a knife for more precise cutting [57, 62]. Similar to APC, electrosurgery has documented efficacy in treatment of malignant airway obstruction [65]. Like laser, both APC and electrosurgery require a low $F_{\mathrm{iO}_{2}}$ $(<0.4)$ to avoid risk of airway fire.

\section{Radiofrequency ablation}

Radiofrequency ablation (RFA) is an alternative form of thermal ablation that nonetheless relies on heat energy to cause tissue necrosis and ultimately cell death $[66,67]$. RFA has been used successfully to treat NSCLC via percutaneous application [68]. Recently, a catheter for bronchoscopic application has become commercially available for use in the United States [69]. In vitro models of bronchoscopic RFA have suggested efficacy, but as yet there are few published data regarding its effectiveness, although it is gaining widespread use in clinical practice [70].

\section{Cryotherapy}

Cryotherapy, also termed cryoablation, is a contact method that relies on the cytotoxic effects of cold rather than heat energy and thus differs from the previously discussed ablative modalities [71]. Nonetheless, it may play a role in the patient with unresectable disease [71]. Initial experience with endobronchial cryotherapy was described in a heterogenous patient population with both benign and malignant causes of airway obstruction [72]. Cryotherapy is effective at achieving haemostasis and may prove useful in patients who will not tolerate a lower $F_{\mathrm{iO}_{2}}$ as there is no risk of airway fire. Cryoablation may be performed feasibly through flexible bronchoscopy, although some operators still prefer use in conjunction with rigid bronchoscopy. Cryoablation has proven effective at palliating symptoms of airway obstruction in patients with unresectable lung cancer [73]. Cryoadhesion is a similar technique whereby the probe is used to adhere to tissue and then remove it from the airway [74]. Spray cryotherapy is a newer method whereby liquid nitrogen gas is sprayed directly onto target tissues to facilitate tissue destruction [74]. Use of spray cryotherapy is not yet widespread, although it is quickly gaining popularity as an ablative technique.

\section{Airway stenting}

Airway stents have been used for patients with airway obstruction for decades, dating back to at least the 1960s [75]. They are indicated in a variety of benign and malignant conditions, and are commonly employed in patients with airway obstruction due to NSCLC. Up to $30 \%$ of patients with advanced lung cancer will develop airway obstruction, thus effective management strategies are crucial [76]. Stents come in a variety of shapes and sizes, with silicone and self-expanding metallic stents (SEMS) being the two primary types [77, 78]. Stents may be used in cases of extrinsic obstruction, where the airway is compressed by tumour in the lung parenchyma or adjacent structures; endoluminal obstruction after appropriate tumour debulking; or mixed obstruction. One key difference in stent selection is that commercially available silicone stents require rigid bronchoscopy for placement, whereas SEMS can be placed using only flexible bronchoscopy and in some cases, fluoroscopy.

Stents are most often employed for palliation of obstruction and are not definitive treatment in and of themselves. As such, stents are often used in combination with other treatment modalities, including radiation or other endobronchial ablative techniques $[79,80]$. Stents are most commonly deployed in the trachea or mainstem bronchi $[77,80]$. Prior to placing a stent, the operator should first determine that 
airways distal to the site of obstruction are patent, otherwise stenting will be of limited or no benefit. Both SEMS and silicone stents have demonstrated efficacy in relieving obstruction in patients with malignant obstruction [78, 81, 82]. Recent attention has focused on placing smaller stents in lobar bronchi for more distal obstruction. While some patients with benign causes of bronchial obstruction have shown symptomatic improvement with this technique, there are few data for this technique in patients with NSCLC and the benefit remains unclear $[83,84]$.

Patients with respiratory failure due to malignant obstruction deserve special attention. The prognosis of patients with lung cancer and respiratory has historically been poor. In one study of 81 patients, only $27 \%$ were successfully weaned from mechanical ventilation, and the in-hospital mortality rate was $85 \%$ [85]. However, in a separate study, patients with advanced NSCLC and malignant central airway obstruction treated with therapeutic bronchoscopy had similar survival to patients with advanced NSCLC without airway obstruction when both received systemic treatment for their malignancy, suggesting a benefit of bronchoscopy in such patients [86]. A few studies have shown that airway stenting can improve outcomes for respiratory failure due to malignant airway obstruction. In one small study of 12 patients with NSCLC, $75 \%$ could be extubated immediately after bronchoscopy and stent placement, with a median survival of 313 days in those successfully extubated [87]. Another study of 50 patients with respiratory failure due to malignant central airway obstruction treated with stents suggested improved survival, but this was only based on comparison with historical controls [88]. Regardless, as in other studies, patients included in this study showed improvement in symptoms and performance status, thus the role for stenting in eligible patients is clear.

Complications of stents include migration, formation of granulation tissue, mucostasis and stent fracture [89]. In general, the rate of complications increases the longer the stent is left in place [89]. In patients undergoing definitive treatment with chemotherapy and/or radiation in which the stent was used as an adjunct therapy, close follow-up is warranted to assess for complications and potentially remove the stent if the patient has shown response to treatment. In those patients in whom stents were placed purely for palliation pursuing a comfort-based approach, the stents are often left in place indefinitely given short life expectancy.

\section{Future directions}

As with other facets of cancer management, bronchoscopic techniques for NSCLC continue to evolve and progress. The past few decades have seen numerous innovations in image-guided bronchoscopy to improve access to peripheral pulmonary nodules. From radial-probe EBUS to electromagnetic navigation (EMN) bronchoscopy, access to peripheral pulmonary nodules via bronchoscopy has continued to improve [90]. The newest iteration of image-guided bronchoscopy is robotic bronchoscopy, where platforms that combine advanced imaging guidance techniques with automated scopes capable of reaching the periphery of the lungs are used to access lesions previously deemed out of reach of conventional bronchoscopic techniques [91]. Initial feasibility studies are promising, even when compared to advanced techniques such as EMN bronchoscopy [91-94]. Robotic and EMN bronchoscopy have traditionally been employed as diagnostic modalities, but great interest exists in leveraging these technologies to apply therapeutic modalities for patients with peripheral nodules who cannot undergo surgical resection. For example, EMN bronchoscopy has been used in animal models to successfully deliver PDT to peripheral lesions [36]. Likewise, image-guided bronchoscopy has been used to deliver radiofrequency ablation to peripheral targets in patients with stage I NSCLC who were deemed not surgical candidates, with good results [95].

Other methods include localised injection, as opposed to systemic administration, of chemotherapeutic agents into tumour tissue [96]. While this technique has shown feasibility, long-term efficacy is not yet known. Personalised airway stents are another area of significant interest. Though not studied extensively in patients with NSCLC, three-dimensional printing to create individualised stents has been used in selected patients with some success [97, 98]. Likewise, biodegradable stents have been used in limited patients with benign disease states to prevent complications of stenting in patients who require longer term airway support $[99,100]$. Whether such technologies offer a significant benefit over conventional airway stents in patients with malignant obstruction remains to be seen.

\section{Conclusion}

In conclusion, patients with unresectable NSCLC often require a multimodal approach to treatment that includes chemotherapy, radiation and potentially bronchoscopic intervention. Bronchoscopic techniques have evolved over the past several decades. PDT and brachytherapy are widely accepted techniques in appropriately selected patients. Various endobronchial ablative techniques may be employed for patients suffering from symptoms of malignant airway obstruction, although they are rarely considered definitive 
therapy. Select patients with malignant airway obstruction may benefit from airway stenting, most likely in combination with ablative techniques. As technology continues to progress, new modalities continue to emerge, particularly for patients with peripheral lung tumours who are not surgical candidates. The treatment landscape for patients should expand as newer investigational techniques become more widely available.

Conflict of interest: C.M. Kniese has nothing to disclose. A.I. Musani received research support from Concordia for the PDT canine study.

\section{References}

1 Centers for Disease Control and Prevention. U.S. Cancer Statistics Data Visualizations Tool, based on November 2018 submission data (1999-2016). 2019. www.cdc.gov/cancer/uscs/dataviz/index.htm

2 O’Neil ME, Henley SJ, Rohan EA, et al. Lung cancer incidence in nonmetropolitan and metropolitan counties United States, 2007-2016. MMWR Morb Mortal Wkly Rep 2019; 68: 993-998.

3 Molina JR, Yang P, Cassivi SD, et al. Non-small cell lung cancer: epidemiology, risk factors, treatment, and survivorship. Mayo Clin Proc 2008; 83: 584-594.

4 Zarogoulidis K, Zarogoulidis P, Darwiche K, et al. Treatment of non-small cell lung cancer (NSCLC). J Thorac Dis 2013; 5: Suppl. 4, S389-S396.

5 Alberg AJ, Brock MV, Ford JG, et al. Epidemiology of lung cancer: diagnosis and management of lung cancer, 3rd ed: American College of Chest Physicians evidence-based clinical practice guidelines. Chest 2013; 143: e1S-e29S.

6 Aberle DR, Adams AM, Berg CD, et al. Reduced lung-cancer mortality with low-dose computed tomographic screening. N Engl J Med 2011; 365: 395-409.

7 Jemal A, Fedewa SA. Lung cancer screening with low-dose computed tomography in the United States - 2010 to 2015. JAMA Oncol 2017; 3: 1278-1281.

8 Nasim F, Sabath BF, Eapen GA. Lung cancer. Med Clin North Am 2019; 103: 463-473.

9 Zheng XQ, Huang JF, Lin JL, et al. Incidence, prognostic factors, and a nomogram of lung cancer with bone metastasis at initial diagnosis: a population-based study. Transl Lung Cancer Res 2019; 8: 367-379.

10 Ramnath N, Dilling TJ, Harris LJ, et al. Treatment of stage III non-small cell lung cancer: diagnosis and management of lung cancer, 3rd ed: American College of Chest Physicians evidence-based clinical practice guidelines. Chest 2013; 143: e314S-e340S.

11 Socinski MA, Evans T, Gettinger S, et al. Treatment of stage IV non-small cell lung cancer: diagnosis and management of lung cancer, 3rd ed: American College of Chest Physicians evidence-based clinical practice guidelines. Chest 2013; 143: e341S-e368S.

12 Howington JA, Blum MG, Chang AC, et al. Treatment of stage I and II non-small cell lung cancer: diagnosis and management of lung cancer, 3rd ed: American College of Chest Physicians evidence-based clinical practice guidelines. Chest 2013; 143: e278S-e313S.

13 Cox JD, Yesner RA. Causes of treatment failure and death in carcinoma of the lung. Yale J Biol Med 1981; 54: 201-207.

14 Mudambi L, Miller R, Eapen GA. Malignant central airway obstruction. J Thorac Dis 2017; 9: S1087-S1110.

15 Chaddha U, Hogarth DK, Murgu S. Bronchoscopic ablative therapies for malignant central airway obstruction and peripheral lung tumors. Ann Am Thorac Soc 2019; 16: 1220-1229.

16 Simone CB 2nd, Cengel KA. Photodynamic therapy for lung cancer and malignant pleural mesothelioma. Semin Oncol 2014; 41: 820-830.

17 Kato H, Okunaka T, Shimatani H. Photodynamic therapy for early stage bronchogenic carcinoma. J Clin Laser Med Surg 1996; 14: 235-238.

18 Simone CB 2nd, Friedberg JS, Glatstein E, et al. Photodynamic therapy for the treatment of non-small cell lung cancer. J Thorac Dis 2012; 4: 63-75.

19 Gomer CJ, Dougherty TJ. Determination of $\left[{ }^{3} \mathrm{H}\right]$ - and $\left[{ }^{14} \mathrm{C}\right]$ hematoporphyrin derivative distribution in malignant and normal tissue. Cancer Res 1979; 39: 146-151.

20 Moghissi K, Dixon K, Stringer M, et al. The place of bronchoscopic photodynamic therapy in advanced unresectable lung cancer: experience of 100 cases. Eur J Cardiothorac Surg 1999; 15: 1-6.

21 Mathur PN, Edell E, Sutedja T, et al. Treatment of early stage non-small cell lung cancer. Chest 2003; 123: 176S-180S.

22 Dougherty TJ, Gomer CJ, Henderson BW, et al. Photodynamic therapy. J Natl Cancer Inst 1998; 90: 889-905.

23 Shepherd RW, Radchenko C. Bronchoscopic ablation techniques in the management of lung cancer. Ann Transl Med 2019; 7: 362.

24 McCaughan JS Jr, Williams TE. Photodynamic therapy for endobronchial malignant disease: a prospective fourteen-year study. J Thorac Cardiovasc Surg 1997; 114: 940-946.

25 Wisnivesky JP, Yung RC, Mathur PN, et al. Diagnosis and treatment of bronchial intraepithelial neoplasia and early lung cancer of the central airways: diagnosis and management of lung cancer, 3rd ed: American College of Chest Physicians evidence-based clinical practice guidelines. Chest 2013; 143: e263S-e277S.

26 Magro CM, Abbas AE, Ross P Jr. The application of photodynamic therapy in the treatment of metastatic endobronchial disease. Lasers Surg Med 2006; 38: 376-383.

27 Miyazu Y, Miyazawa T, Kurimoto N, et al. Endobronchial ultrasonography in the assessment of centrally located early-stage lung cancer before photodynamic therapy. Am J Respir Crit Care Med 2002; 165: 832-837.

28 Hugh-Jones P, Gardner WN. Laser photodynamic therapy for inoperable bronchogenic squamous carcinoma. Q J Med 1987; 64: 565-581.

29 Cortese DA, Edell ES, Kinsey JH. Photodynamic therapy for early stage squamous cell carcinoma of the lung. Mayo Clinic Proc 1997; 72: 595-602.

30 Diaz-Jiménez JP, Martínez-Ballarín JE, Llunell A, et al. Efficacy and safety of photodynamic therapy versus NdYAG laser resection in NSCLC with airway obstruction. Eur Respir J 1999; 14: 800-805. 
Moghissi K, Dixon K, Thorpe JA, et al. Photodynamic therapy (PDT) in early central lung cancer: a treatment option for patients ineligible for surgical resection. Thorax 2007; 62: 391-395.

Minnich DJ, Bryant AS, Dooley A, et al. Photodynamic laser therapy for lesions in the airway. Ann Thorac Surg 2010; 89: 1744-1748.

Cai XJ, Li WM, Zhang LY, et al. Photodynamic therapy for intractable bronchial lung cancer. Photodiagnosis Photodyn Ther 2013; 10: 672-676.

Usuda J, Kato H, Okunaka T, et al. Photodynamic therapy (PDT) for lung cancers. J Thorac Oncol 2006; 1: 489-493. Weinberg BD, Allison RR, Sibata C, et al. Results of combined photodynamic therapy (PDT) and high dose rate brachytherapy (HDR) in treatment of obstructive endobronchial non-small cell lung cancer (NSCLC). Photodiagnosis Photodyn Ther 2010; 7: 50-58.

Musani AI, Veir JK, Huang Z, et al. Photodynamic therapy via navigational bronchoscopy for peripheral lung cancer in dogs. Lasers Surg Med 2018; 50: 483-490.

Raben A, Mychalczak B. Brachytherapy for non-small cell lung cancer and selected neoplasms of the chest. Chest 1997; 112: 276S-286S.

Stewart A, Parashar B, Patel M, et al. American Brachytherapy Society consensus guidelines for thoracic brachytherapy for lung cancer. Brachytherapy 2016; 15: 1-11.

Mallow C, Hayes M, Semaan R, et al. Minimally invasive palliative interventions in advanced lung cancer. Expert Rev Respir Med 2018; 12: 605-614.

Rodrigues G, Videtic GM, Sur R, et al. Palliative thoracic radiotherapy in lung cancer: an American Society for Radiation Oncology evidence-based clinical practice guideline. Pract Radiat Oncol 2011; 1: 60-71.

Lo TC, Beamis JF Jr, Weinstein RS, et al. Intraluminal low-dose rate brachytherapy for malignant endobronchial obstruction. Radiother Oncol 1992; 23: 16-20.

Nori D, Allison R, Kaplan B, et al. High dose-rate intraluminal irradiation in bronchogenic carcinoma. Technique and results. Chest 1993; 104: 1006-1011.

Pérol M, Caliandro R, Pommier P, et al. Curative irradiation of limited endobronchial carcinomas with high-dose rate brachytherapy. Results of a pilot study. Chest 1997; 111: 1417-1423.

Ofiara L, Roman T, Schwartzman K, et al. Local determinants of response to endobronchial high-dose rate brachytherapy in bronchogenic carcinoma. Chest 1997; 112: 946-953.

Taulelle M, Chauvet B, Vincent $\mathrm{P}$, et al. High dose rate endobronchial brachytherapy: results and complications in 189 patients. Eur Respir J 1998; 11: 162-168.

Marsiglia H, Baldeyrou P, Lartigau E, et al. High-dose-rate brachytherapy as sole modality for early-stage endobronchial carcinoma. Int J Radiat Oncol Biol Phys 2000; 47: 665-672.

Kelly JF, Delclos ME, Morice RC, et al. High-dose-rate endobronchial brachytherapy effectively palliates symptoms due to airway tumors: the 10-year M. D. Anderson Cancer Center experience. Int J Radiat Oncol Biol Phys 2000; 48: 697-702.

Gejerman G, Mullokandov EA, Bagiella E, et al. Endobronchial brachytherapy and external-beam radiotherapy in patients with endobronchial obstruction and extrabronchial extension. Brachytherapy 2002; 1: 204-210.

Hennequin C, Bleichner O, Trédaniel J, et al. Long-term results of endobronchial brachytherapy: a curative treatment? Int J Radiat Oncol Biol Phys 2007; 67: 425-430.

Guarnaschelli JN, Jose BO. Palliative high-dose-rate endobronchial brachytherapy for recurrent carcinoma: the University of Louisville experience. J Palliat Med 2010; 13: 981-989.

Aumont-le Guilcher M, Prevost B, Sunyach MP, et al. High-dose-rate brachytherapy for non-small-cell lung carcinoma: a retrospective study of 226 patients. Int J Radiat Oncol Biol Phys 2011; 79: 1112-1116.

Goldberg M, Timotin E, Farrell T, et al. A prospective analysis of high-dose-rate endobronchial brachytherapy in the palliation of obstructive symptoms in lung cancer patients: A single-institution experience. Brachytherapy 2015; 14: 655-661.

Chella A, Ambrogi MC, Ribechini A, et al. Combined Nd-YAG laser/HDR brachytherapy versus Nd-YAG laser only in malignant central airway involvement: a prospective randomized study. Lung Cancer 2000; 27: 169-175.

Zaric B, Perin B, Jovelic A, et al. Clinical risk factors for early complications after high-dose-rate endobronchial brachytherapy in the palliative treatment of lung cancer. Clin Lung Cancer 2010; 11: 182-186.

Hara R, Itami J, Aruga T, et al. Risk factors for massive hemoptysis after endobronchial brachytherapy in patients with tracheobronchial malignancies. Cancer 2001; 92: 2623-2627.

Khanavkar B, Stern P, Alberti W, et al. Complications associated with brachytherapy alone or with laser in lung cancer. Chest 1991; 99: 1062-1065.

Sachdeva A, Pickering EM, Lee HJ. From electrocautery, balloon dilatation, neodymium-doped:yttrium-aluminumgarnet (Nd:YAG) laser to argon plasma coagulation and cryotherapy. J Thorac Dis 2015; 7: Suppl. 4, S363-S379.

Dumon JF, Reboud E, Garbe L, et al. Treatment of tracheobronchial lesions by laser photoresection. Chest 1982; 81: 278-284.

Shapshay SM, Dumon JF, Beamis JF Jr. Endoscopic treatment of tracheobronchial malignancy. Experience with Nd-YAG and $\mathrm{CO}_{2}$ lasers in 506 operations. Otolaryngol Head Neck Surg 1985; 93: 205-210. 1,000 patients. Chest 1988; 94: 15-21.

Farin G, Grund KE. Technology of argon plasma coagulation with particular regard to endoscopic applications. Endosc Surg Allied Technol 1994; 2: 71-77.

Mahajan AK, Ibrahim O, Perez R, et al. Electrosurgical and laser therapy tools for the treatment of malignant central airway obstructions. Chest 2020; 157: 446-453.

Morice RC, Ece T, Ece F, et al. Endobronchial argon plasma coagulation for treatment of hemoptysis and neoplastic airway obstruction. Chest 2001; 119: 781-787.

Crosta C, Spaggiari L, De Stefano A, et al. Endoscopic argon plasma coagulation for palliative treatment of malignant airway obstructions: early results in 47 cases. Lung Cancer 2001; 33: 75-80.

Sutedja G, van Kralingen K, Schramel FM, et al. Fibreoptic bronchoscopic electrosurgery under local anaesthesia for rapid palliation in patients with central airway malignancies: a preliminary report. Thorax 1994; 49: 1243-1246. Hartley-Blossom ZJ, Healey TT. Percutaneous thermal ablation for lung cancer: an update. Surg Technol Int 2019; 34: 359-364. 
Sabath BF, Casal RF. Bronchoscopic ablation of peripheral lung tumors. J Thorac Dis 2019; 11: 2628-2638.

Gao Y, Chen J, Zhang J, et al. Radiofrequency ablation of primary non-small cell lung cancer: a retrospective study on 108 patients. J BUON 2019; 24: 1610-1618.

Medtronic. CoreCath Product Information Sheet. 2017 Date last accessed: January 4, 2020. www.medtronic. $\mathrm{com} /$ content/dam/covidien/library/us/en/product/interventional-lung-solutions/corecath-2-7s-electrosurgicaldevice-information-sheet.pdf.

Safi S, Op den Winkel J, Kramer S, et al. A new bronchoscopic catheter for the transbronchial ablation of pulmonary nodules. Lung Cancer 2018; 124: 125-129.

Vergnon JM, Huber RM, Moghissi K. Place of cryotherapy, brachytherapy and photodynamic therapy in therapeutic bronchoscopy of lung cancers. Eur Respir J 2006; 28: 200-218.

Mathur PN, Wolf KM, Busk MF, et al. Fiberoptic bronchoscopic cryotherapy in the management of tracheobronchial obstruction. Chest 1996; 110: 718-723.

Asimakopoulos G, Beeson J, Evans J, et al. Cryosurgery for malignant endobronchial tumors: analysis of outcome. Chest 2005; 127: 2007-2014.

DiBardino DM, Lanfranco AR, Haas AR. Bronchoscopic cryotherapy. Clinical applications of the cryoprobe, cryospray, and cryoadhesion. Ann Am Thorac Soc 2016; 13: 1405-1415. 2015; 12: 631-641.

Ernst A, Feller-Kopman D, Becker HD, et al. Central airway obstruction. Am J Respir Crit Care Med 2004; 169: 1278-1297.

Avasarala SK, Freitag L, Mehta AC. Metallic endobronchial stents: a contemporary resurrection. Chest 2019; 155: 1246-1259.

Semaan R, Yarmus L. Rigid bronchoscopy and silicone stents in the management of central airway obstruction. J Thorac Dis 2015; 7: S352-S362.

Mallow C, Thiboutot J, Semaan R, et al. External beam radiation therapy combined with airway stenting leads to better survival in patients with malignant airway obstruction. Respirology 2018; 23: 860-865.

Chen $\mathrm{CH}$, Wu BR, Cheng WC, et al. Interventional pulmonology for patients with central airway obstruction: an 8-year institutional experience. Medicine 2017; 96: e5612.

Breitenbücher A, Chhajed PN, Brutsche $\mathrm{MH}$, et al. Long-term follow-up and survival after Ultraflex stent insertion in the management of complex malignant airway stenoses. Respiration 2008; 75: 443-449.

Dutau H, Toutblanc B, Lamb C, et al. Use of the Dumon Y-stent in the management of malignant disease involving the carina: a retrospective review of 86 patients. Chest 2004; 126: 951-958.

Fruchter O, Abed El Raouf B, Rosengarten D, et al. Long-term outcome of short metallic stents for lobar airway stenosis. J Bronchology Interv Pulmonol 2017; 24: 211-215.

Sethi S, Gildea TR, Almeida FA, et al. Clinical success stenting distal bronchi for "lobar salvage" in bronchial stenosis. J Bronchology Interv Pulmonol 2018; 25: 9-16.

Lin YC, Tsai YH, Huang CC, et al. Outcome of lung cancer patients with acute respiratory failure requiring mechanical ventilation. Respir Med 2004; 98: 43-51. central airway obstruction. Chest 2006; 130: 1803-1807. Murgu S, Langer S, Colt H. Bronchoscopic intervention obviates the need for continued mechanical ventilation in patients with airway obstruction and respiratory failure from inoperable non-small-cell lung cancer. Respiration 2012; 84: 55-61.

Razi SS, Lebovics RS, Schwartz G, et al. Timely airway stenting improves survival in patients with malignant central airway obstruction. Ann Thorac Surg 2010; 90: 1088-1093.

Zakaluzny SA, Lane JD, Mair EA. Complications of tracheobronchial airway stents. Otolaryngol Head Neck Surg 2003; 128: 478-488.

Shepherd RW. Bronchoscopic pursuit of the peripheral pulmonary lesion: navigational bronchoscopy, radia endobronchial ultrasound, and ultrathin bronchoscopy. Curr Opin Pulm Med 2016; 22: 257-264. from the initial multicenter experience. BMC Pulm Med 2019; 19: 243.

Chen AC, Pastis NJ, Machuzak MS, et al. Accuracy of a robotic endoscopic system in cadaver models with simulated tumor targets: ACCESS study. Respiration 2020; 99: 56-61.

Fielding DIK, Bashirzadeh F, Son JH, et al. First human use of a new robotic-assisted fiber optic sensing navigation system for small peripheral pulmonary nodules. Respiration 2019; 98: 142-150.

Yarmus L, Akulian J, Wahidi $\mathrm{M}$, et al. A prospective randomized comparative study of three guided bronchoscopic approaches for investigating pulmonary nodules: the PRECISION-1 study. Chest 2020; 157: 694-701.

Koizumi T, Tsushima K, Tanabe T, et al. Bronchoscopy-guided cooled radiofrequency ablation as a novel intervention therapy for peripheral lung cancer. Respiration 2015; 90: 47-55.

Yarmus L, Mallow C, Akulian J, et al. Prospective multicentered safety and feasibility pilot for endobronchial intratumoral chemotherapy. Chest 2019; 156: 562-570.

$\mathrm{Xu}$ J, Ong HX, Traini D, et al. The utility of 3D-printed airway stents to improve treatment strategies for central airway obstructions. Drug Dev Ind Pharm 2019; 45: 1-10.

Gildea TR, Young BP, Machuzak MS. Application of 3D printing for patient-specific silicone stents: 1-year follow-up on 2 patients. Respiration 2018; 96: 488-494.

Dutau H, Musani AI, Laroumagne S, et al. Biodegradable airway stents - bench to bedside: a comprehensive review. Respiration 2015; 90: 512-521.

Zając A, Krysta M, Kiszka A, et al. Biodegradable airway stents: novel treatment of airway obstruction in children. Adv Clin Exp Med 2019; 28: 961-965. 